\title{
Still's disease associated with adenovirus infection and defect in adenovirus directed natural killing
}

\author{
ANTHONY S LUDER, ${ }^{1}$ VERA NAPHTALI, ${ }^{2}$ EDNA BEN PORAT, ${ }^{2}$ AND \\ NITZA LAHAT \\ From the ${ }^{1}$ Department of Pediatrics and Pediatric Research Unit and Immunology Research Unit, Carmel \\ Hospital (Faculty of Medicine, Technion-Israel Institute of Technology), and the 2Department of Virology, \\ Rambam Hospital, Haifa, Israel
}

SUMMARY Low natural killer (NK) activity towards adenovirus infected fibroblasts was detected in the peripheral blood of a child with Still's disease and was not normalised by the addition of interferon alfa or interleukin 2 . NK cytotoxicity directed at K 562 target cells or polio infected fibroblasts was normal. This specific NK deficiency might have contributed to the development of the child's Still's disease.

Systemic onset juvenile chronic arthritis (Still's disease) remains a common and puzzling problem. ${ }^{1}$ Although many attempts have been made to identify the important aetiological factors, the cause(s), as with other connective tissue disease, remains unknown. ${ }^{2}$ Among the large variety of putative infectious agents studied $^{3-9}$ are viruses. Febrile arthritides, usually self limited, can be caused by virus, including adenovirus. ${ }^{8}$ On rare occasions chronic erosive arthritides have followed infection with hepatitis B and rubella viruses. ${ }^{910}$ Success in isolating viruses by culture in patients with rheumatoid arthritis has been extremely limited, though indirect methods of viral identification have occasionally been successful. ${ }^{11}$ Recently, parvovirus was detected in the synovium of one patient with rheumatoid arthritis, ${ }^{12}$ and adenovirus isolated from a girl who developed juvenile rheumatoid arthritis. ${ }^{13}$ No other associations between juvenile rheumatoid arthritis or Still's disease and adenovirus infection have been described as far as we know. Recent studies have emphasised the range of immune disturbances commonly seen in these patients, 314 defects which may also have important pathogenetic significance. We report a case of Still's disease, in which an initiating infection with adenovirus was recorded together with a defect in adenovirus directed natural killing.

\section{Case report}

A 15 month old Ashkenazi-Jewish male child presented with prolonged fever, rash, and transient

Accepted for publication 12 January 1989.

Correspondence to Dr Nitza Lahat. Immunology Research Unit. Lady Davis Carmel Hospital. 7 Michal Street, Haifa 34362. Israel. arthritis. He had been born in Israel but had lived in Nigeria until this illness. At 6 months of age he had been successfully treated with chloroquine for a febrile illness, diagnosed as malaria. At 9 months he had a transient episode of swelling and tenderness of the left elbow, which passed spontaneously after 12 hours. At 14 months he developed a swinging fever up to $41^{\circ} \mathrm{C}$ with rigors and a faint pink macular rash on the trunk, which appeared three times a day with fever spikes. The child appeared well between spikes. He was admitted to hospital. Bilateral serous otitis media was present, and the liver and spleen were palpable $3 \mathrm{~cm}$ below the costal margin. Lymph nodes, mucous membranes, and eyes were normal. Investigations showed haemoglobin $103 \mathrm{~g} / \mathrm{l}$, mean cell volume $89 \mathrm{fl}$, leucocytes $12900 \times 10^{9} / 1$ (18\% stab forms, $43 \%$ neutrophils) and $422 \times 10^{9} / 1$ platelets. The erythrocyte sedimentation rate was accelerated at $145 \mathrm{~mm}$ in the first hour, $C$ reactive protein grossly raised, ferritin was $1160 \mu \mathrm{g} / \mathrm{l}$, while immunoglobulin and complement concentrations were normal. Blood culture studies were negative, as were extensive serological and skin antigen tests. No autoantibodies were detected. Bone marrow examination showed a myeloid:erythroid ratio of $4: 1$ and $23 \%$ of white cells were plasma cells. A diagnosis of Still's disease was made, and treatment was started with aspirin $50 \mathrm{mg} / \mathrm{kg}$ with good clinical response. At the same time both parents, an elder brother ( 5 years), and one grandmother became ill with a febrile flu-like illness, which resolved within 7-10 days. A urine virus culture obtained from the patient at admission now grew adenovirus, but cultures of stool and throat were negative. All the ill family members showed greater than fourfold rises 
in antiadenovirus titres, except the patient. Only two months after his remission and three months after positive adenovirus culture was a fourfold rise in titre observed. During one year of follow up there have been three relapses, both associated with subtherapeutic aspirin levels and both responding to an increased dose. The isolation of adenovirus in combination with an apparently defective antibody response prompted us to investigate his immune system in greater detail.

\section{IMMUNE STUDIES}

Peripheral blood lymphocytes were isolated from fresh heparinised blood by Ficoll-Hypaque density gradient centrifugation. Phenotypes were studied by indirect fluorescent staining using the following monoclonal antibodies: antihuman CD8 (T suppressor/cytotoxic), antihuman Leu $11 \mathrm{~b}$ (natural killer (NK) cells), and antihuman Leu 12 (B cells). All monoclonal antibodies were obtained from BectonDickinson (Mountain View, CA, USA). The cells bearing these surface antigens were counted in fresh blood and after seven days' incubation with standard adenovirus antigen in the highest dilution. Proliferation was determined in peripheral blood lymphocyte cultures using optimal and suboptimal mitogen concentrations of phytohaemagglutinin (PHA-P, Difco, Detroit, Michigan, USA), concanavalin A (Sigma, St Louis, Missouri, USA), pokeweed mitogen (Sigma, St Louis, USA), and Staphylococcus aureus (Calbiochem, La Jolla, CA, USA) for 72 or 96 hours, or various dilutions of adenovirus for seven days. This culture was performed on isolated $\mathrm{T}$ cells $+5 \%$ autologous monocytes. $\mathrm{T}$ cells were isolated from non-adherent peripheral blood lymphocytes after EAT rosetting. ${ }^{15}$ Monocytes were isolated with rubber policemen from adherent peripheral blood lymphocytes. ${ }^{16}$ The medium was RPMI $1640+10 \%$ fetal calf serum $+1 \%$ antibiotics (complete medium). We used standard adenovirus antigen (Behringwerke AG, Germany) titre 1/64 and adenovirus isolated from the patient's urine on human embryo fibroblasts. Identification of the isolated virus was performed by complement fixation test using high titre human serum. Eighteen hours before cultures were stopped $\left[{ }^{3} \mathrm{H}\right]$ thymidine was added, and radioactivity incorporated into nascent DNA was read in a beta scintillation counter. Peripheral blood lymphocytes were subjected to adherence on plastic Petri dishes. ${ }^{16}$ Non-adherent cells were collected and used for cytotoxicity or were subjected to two cycles of monoclonal antibodies plus complement mediated lysis. The monoclonal antibodies used for this procedure were anti-CD3 and anti-CD4 or Leu 11b. Viable cells were investigated for fluorescence with the same monoclonal antibodies. Less than $5 \% \mathrm{CD}^{+}$cells remained afte depletion of CD3 and CD4 lymphocytes. Less tha $1 \%$ Leu $11 \mathrm{~b}$ cells were detected after Leu $11 \mathrm{~b}$ cell depletion. These subpopulations of T or NK deplete lymphocytes were used in cytotoxicity tests. Secretion of interleukin 2 was measured according to Kapplef et al. ${ }^{17}$

The response of cytotoxic activity to exogenows interleukin 2 and interferon alfa (Israel Institufe for Biological Research, Ness Ziona, Israel) w\&ీ measured by the method of Herberman. ${ }^{18}$ Peripherạ blood lymphocytes were incubated with interleukin 2 for 18 hours and with interferon alfa for two hours and then washed and suspended for the cytotoxiciny assays. Target cells for the cytotoxicity assays were

Table 1 Immunological tests. Values are given as mean (SD)

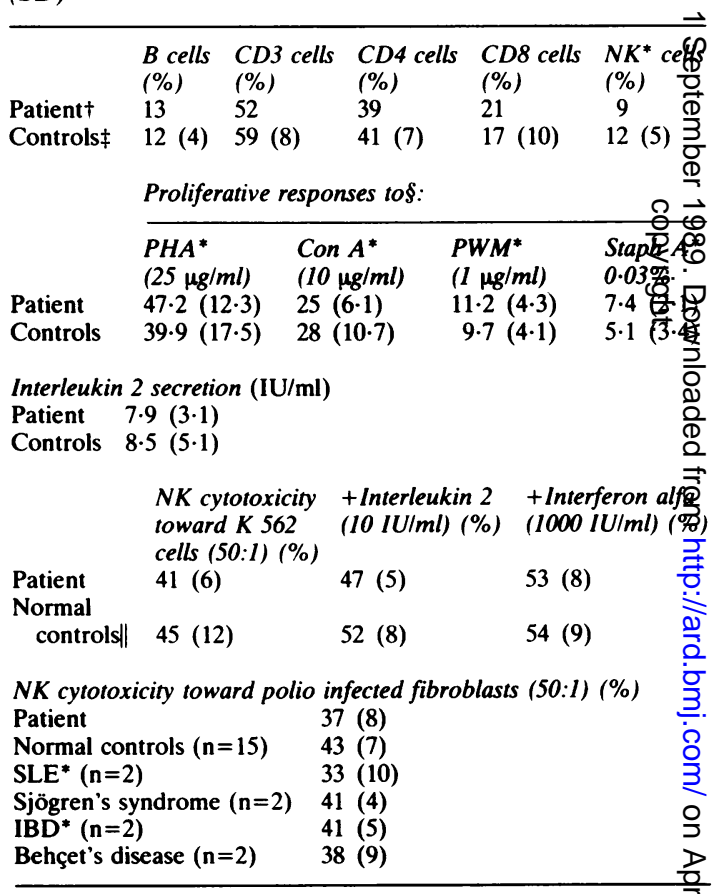

*NK=natural killer; PHA=phytohaemagglutinin; Con $A=$ cơrcanavilin A; PWM=pokeweed mitogen; Staph A=StaphylococGS aureus (strain Cowan A); SLE=systemic lupus erythematosus; IBD = inflammatory bowel disease.

tThe patient's results presented were obtained in remission, they are not significantly different from those obtained durugg adenovirus infection.

¥Intrafamilial and extrafamilial controls.

\$Measured in stimulation indices: $\mathrm{cpm}$ with mitogen/cpm with fot mitogen.

|NK cytotoxicity test was performed in autoimmune inflammatory controls too, and patients with SLE and Sjögren's syndrome hăd low values. 
A

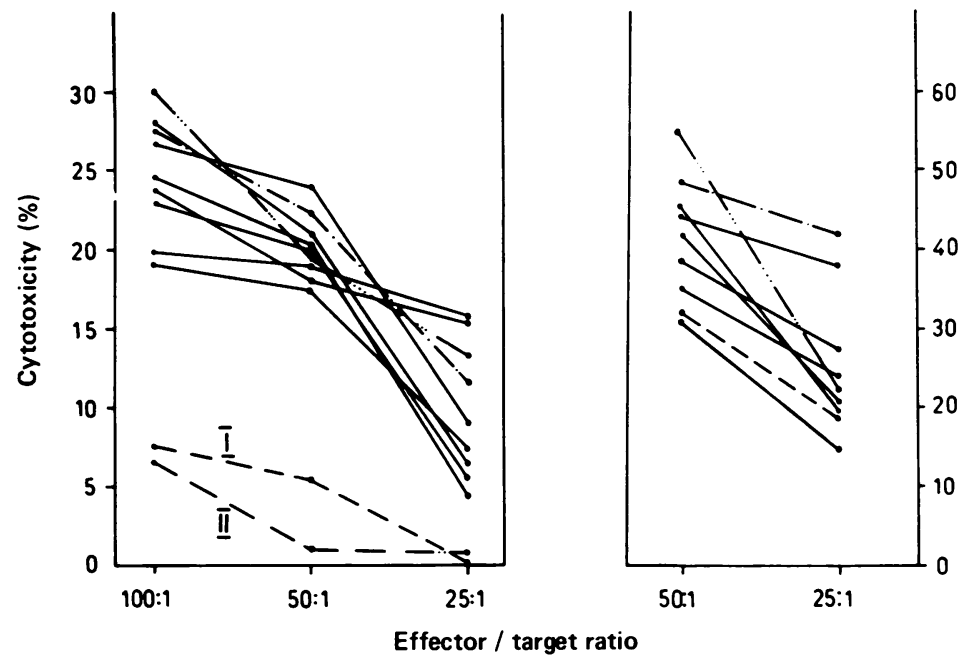

Fig. 1 Cytotoxic lymphocyte responses towards $(A)$ adenovirus infected fibroblasts and $(B) K 562$ target cell line. Cytotoxicity tests were performed at 100:1, 50:1, and 25:1 effector:target ratios and are presented as net percentage of ${ }^{51} \mathrm{Cr}$ released from target cells. The patient was studied twice for adenovirus specific cytotoxicity. ---- patient $(I=$ acute stage; $I I=$ remission stage); $-\cdot-\cdot=$ mother of patient; - $\cdots-=$ brother of patient; $=$ controls. The results presented are with fibroblasts infected with the child's own isolated adenovirus. Essentially the same results are obtained with standard adenovirus. low passage human embryonic fibroblasts. Fibroblast monolayers were either mock infected or infected with standard adenovirus or adenovirus isolated from the patient or with standard polio virus. Virus suspension was absorbed on the monolayer for two hours and further incubated at $37^{\circ} \mathrm{C}$ in minimal essential medium containing $2 \%$ fetal calf serum for four days, or for two days in the case of polio infected cells. Monolayers were harvested when $25-50 \%$ of the cells showed cytopathic effect. The monolayers were trypsinised, washed, and labelled for 1 hour with $5.6 \mathrm{MBq}{ }^{51} \mathrm{Cr}\left(\right.$ as $\left.\mathrm{NaCrO}_{4}\right)$. Then they were washed thoroughly and dispensed in $\mathrm{U}$ bottom microtitre plates immediately before effector lymphocytes were added to yield duplicate determinations of effector to target of 100:1, 50:1, and $25: 1$. The plates were incubated at $37^{\circ} \mathrm{C}$ for 14 hours and radioactivity determined in a $j$ spectrometer. The ${ }^{51} \mathrm{Cr}$ release was calculated as follows:

$$
\begin{aligned}
& \% \text { Lysis }\left({ }^{51} \mathrm{Cr} \text { release }\right)= \\
& \frac{\text { experimental }{ }^{51} \mathrm{Cr} \text { release-spontaneous }{ }^{51} \mathrm{Cr} \text { release }}{\text { maximum }{ }^{51} \mathrm{Cr} \text { release-spontaneous }{ }^{51} \mathrm{Cr} \text { release }}
\end{aligned}
$$

where maximum release $=$ the release in the presence of $0.5 \%$ Triton; spontaneous release $=$ the release from target cells incubated with medium.

Spontaneous release from infected cells was always higher than from non-infected fibroblasts. Maximum release was not significantly different in infected and non-infected fibroblasts, and we used the results of infected fibroblasts only. The results

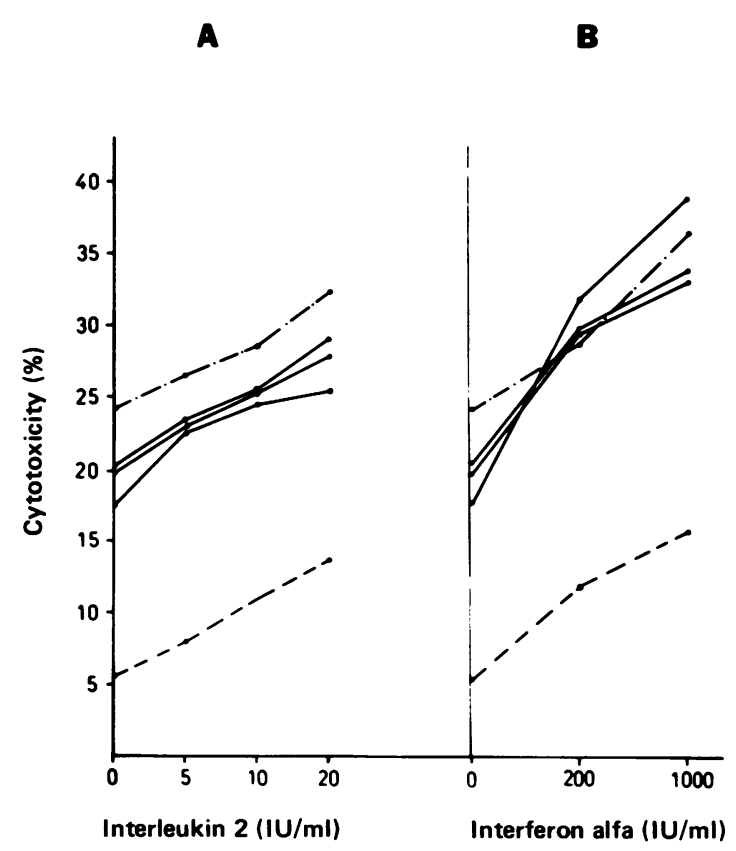

Fig. 2 Enhancing effect of $(A)$ interleukin 2 and $(B)$ interferon alfa on lymphocyte cytotoxicity. Cytotoxicity tests were performed at a 50:1 effector:target ratio after peripheral blood lymphocytes had been preincubated for 18 hours (interleukin 2) or two hours (interferon alfa). Results are presented as net percentage of ${ }^{51} \mathrm{Cr}$ released from target cells. $----=$ patient $;-\cdot-\cdot=$ mother of patient; $\longrightarrow$ controls. 
are expressed as net percentage cytotoxicity, which is the percentage of ${ }^{51} \mathrm{Cr}$ released from virus infected over non-infected fibroblasts. Natural killer assays against the non-adherent $\mathrm{K} 562$ cells were carried out as for virus infected fibroblasts, except that incubation was for four hours instead of 14 hours.

\section{Results}

General assessment of the immune system was carried out as follows: $(a)$ by estimation of the percentage of B cells, total T cells, $T$ cell subpopulations, and NK cells in peripheral blood lymphocytes; (b) by proliferation of $\mathrm{T}$ cells to the mitogens phytohaemagglutinin and concanavalin $A$, of $T$ and $B$ cells to pokeweed mitogen, and $B$ cells to Staphylococcus aureus (strain Cowan A); (c) by production of interleukin $2 ;(d)$ by natural killing and its stimulation by interleukin 2 and interferon alfa towards K 562 and by natural killing towards polio infected target cells. In these examinations no difference was observed between the patient and controls (Table 1).

Specific in vitro cytotoxicity of lymphocytes from the patient against fibroblast targets infected with
Table 2 Percentage of peripheral blood lymphocyte cytotoxicity to adenovirus infected fibroblasts. Values are given as mean $(S D)$

\begin{tabular}{|c|c|c|c|}
\hline & $P B L^{*}$ & $\begin{array}{l}T \text { cell } \\
\text { depleted } \\
P B L \dagger\end{array}$ & $\begin{array}{l}N K^{*} \text { celt } \\
\text { depleted } \\
P B L\end{array}$ \\
\hline Patient & $7 \cdot 3$ & 5.9 & $3 \cdot 2$ \\
\hline During remission & $2 \cdot 1$ & $5 \cdot 7$ & $2 \cdot 0$ \\
\hline Mother & $25 \cdot 5$ & $20 \cdot 5$ & $7 \cdot 0$ \\
\hline During remission & 23.4 & $19 \cdot 8$ & $4 \cdot 2$ \\
\hline Brother & $20 \cdot 5$ & $22 \cdot 0$ & $5 \cdot 3$ \\
\hline $\begin{array}{l}\text { Normal age matched } \\
\text { controls }(n=7)\end{array}$ & $23.5(5.4)$ & $19 \cdot 8(4 \cdot 7)$ & 4.6 (3. 2े \\
\hline $\begin{array}{l}\text { Normal adult } \\
\text { controls }(n=9)\end{array}$ & $24 \cdot 2(4 \cdot 6)$ & $18 \cdot 7(4 \cdot 5)$ & $5 \cdot 1$ (2.\& \\
\hline $\operatorname{IBD}^{*}(n=2)$ & $21.7(3.4)$ & $21 \cdot 2(5 \cdot 5)$ & 7.4 (3. बि \\
\hline $\begin{array}{l}\text { Sjögren's syndrome } \\
(\mathrm{n}=2)\end{array}$ & $19 \cdot 4(5 \cdot 1)$ & $16 \cdot 1(4 \cdot 4)$ & $5.7(4.2 b$ \\
\hline $\operatorname{SLE}^{*}(n=2)$ & $20.6(3.1)$ & $17 \cdot 9(4 \cdot 2)$ & $6.3(3.1)$ \\
\hline $\begin{array}{l}\text { Behçet's } \\
\text { disease }(n=2)\end{array}$ & $23 \cdot 8(4 \cdot 0)$ & $19 \cdot 3(5 \cdot 5)$ & $4.6(2$ \\
\hline
\end{tabular}

*PBL=peripheral blood lymphocytes; NK=natural killer; IBD $\Theta$ inflammatory bowel disease; SLE =systemic lupus erythematosu 8 †Non-adherent peripheral blood lymphocytes were subjected two cycles of incubation with monoclonal antibodies and complement to eliminate cells bearing T or NK surface antigen and then viable cells were tested for cytotoxicity in a ratio of $50 \%$ effector:target.

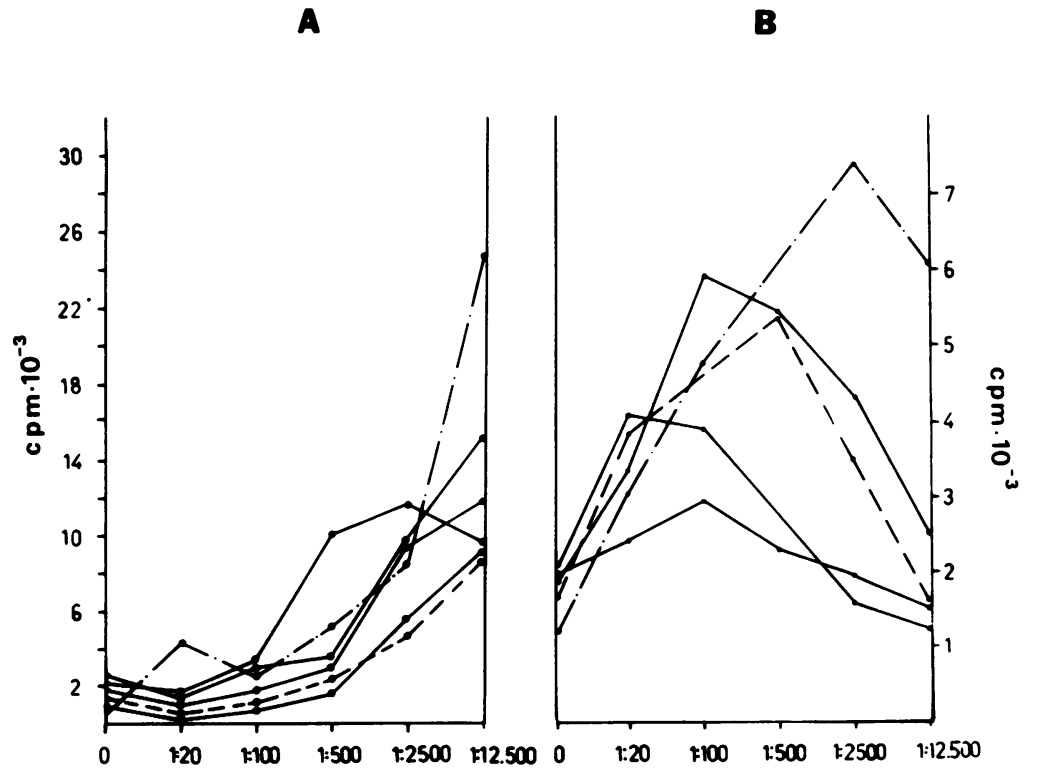

Virus dilution
Fig. 3 Proliferative responses of $T$ cells $(+5 \%$ monocytes) to adenovirus. $T$ cells $+5 \%$ analogous monocytes were incubated for seven days with dilution of $(A)$ standard adenovirus or $(B)$ adenovirus isolated from the patient's urine. Results are expressed as cpm $\times 10{ }^{3}$ of $\left.l^{3} \mathrm{H}\right]$ thymidine incorporated in nascent DNA of proliferating lymphocytes. $---=$ patient; or - - - = mother; 
the adenovirus isolated from his own urine and a standard adenovirus preparation was examined, both at the time of the acute illness when live virus was present and again three months later when he was in remission and the urine sterile (Fig. 1). A marked and specific reduction in cytotoxicity was observed with the patient's cells on both occasions and at three effector:target ratios, as against his mother, brother, and controls. In vitro deficient NK activity may occur after a lack of response or a poor response to immunomodulators like interleukin 2 or interferon alfa. Interleukin 2 production by the patient's peripheral blood lymphocytes was normal. Cytotoxicity experiments with added interleukin 2 and interferon alfa showed normal increases in all subjects against $\mathrm{K} 562$ targets (Table 1) and isolated adenovirus (Fig. 2). In the last case, however, the patient's response was markedly depressed at all dilutions compared with controls. In experiments designed to identify the phenotype of effector cells in the adenovirus induced cytotoxic system the cytotoxicity studies were repeated with selected subpopulations of cells after NK or T cell depletion. In all subjects tested the greater part of the cytotoxic activity was concentrated among cells bearing surface antigens marking NK cells, and not in cells bearing the CD3 antigens (Table 2). In addition to cytotoxicity studies, the proliferative response of peripheral blood lymphocytes after stimulation by standard adenovirus and the patient's adenovirus at different dilutions was measured. No clear difference between the patient and controls could be discerned (Fig. 3). In contrast with the NK phenotype, which dominated the cytotoxicity activity, most of the virus stimulated proliferative activity was found among cells bearing antigens specific to suppressor/cytotoxic $T$ cells. There was no difference in the response of the patient's peripheral blood lymphocytes between the acute phase and remission. In all subjects the ratio of CD4:CD8 cells (helper:suppressor) was lower after culture than in fresh cells (Table 3 ).

Table 3 Percentage of $T$ cell markers before and after culture with adenovirus

\begin{tabular}{lllll}
\hline & & $\begin{array}{l}\text { CD4 } \\
\text { (helper) } \\
\text { inducer) }\end{array}$ & $\begin{array}{l}\text { CD8 } \\
\text { (suppressorl } \\
\text { cytotoxic) }\end{array}$ & CD4/CD8 \\
\hline Patient & Fresh & $36\left(39^{*}\right)$ & $31(21)$ & $1 \cdot 16(1 \cdot 85)$ \\
& Cultured & $31(26)$ & $48(44)$ & $0.64(0 \cdot 6)$ \\
Mother & Fresh & $40\left(41^{*}\right)$ & $26(20)$ & $1 \cdot 53(2 \cdot 05)$ \\
Controls & Cultured & $36(32)$ & $52(59)$ & $0 \cdot 69(0 \cdot 54)$ \\
$(n=5)$ & Cultured & 41 (SD 8) & 23 (SD 6) & $1 \cdot 78$ \\
& Cu 7) & 47 (SD 9) & 0.82 \\
\hline
\end{tabular}

*Patient and mother were studied twice. The values in parentheses are the results during the remission phase.
Although T cell cytotoxicity was not estimated, it seems that the quality and characteristics of $T$ cell responses to adenovirus were similar in the patient and normal controls.

\section{Discussion}

We have reported a case of Still's disease in which adenovirus infection was recorded at the outset as there was a family outbreak. The gross immune system of the child was intact, with normal humoral function and normal $T$ cell subpopulations and responsive proliferation to mitogens. NK cytotoxicity was normal when measured against K 562 and polio infected targets but was deficient in the index case as against intrafamilial and extrafamilial controls when directed at target cells infected with his own or standard adenovirus, both in the acute and remission phases of the disease. The specific deficiency seemed to be concentrated in a subpopulation of cells characterised by surface antigens marking NK cells. Measurement of interleukin 2 secretion, and cytotoxicity experiments carried out with added interleukin 2 or interferon alfa, do not support the possibility that reduced synthesis or deficient response to these immunomodulators were responsible for the low NK activity. Rather, a functional intrinsic defect in adenovirus directed NK lymphocytes is suggested. Such specific NK deficiencies are known to be associated clinically with an increased susceptibility to and protracted course of viral infections. ${ }^{19}{ }^{20}$ As far as we know, deficiency of NK activity directed against virus infected target cells has not been previously reported in Still's disease, though other defects in cell mediated immunity have been described in adult rheumatoid arthritis. ${ }^{14}$ Whether this loss of activity is primary or secondary, or how it might occur, is unknown. Although adenovirus infection together with specific disturbed immunity towards this virus might have caused Still's disease in this child, two other possibilities should be mentioned: a self limited postviral disorder caused by adenovirus infection, or adenovirus infection coincidental in a patient with Still's disease.

\section{References}

1 Calabro J J. Juvenile rheumatoid arthritis. Mode of onset as key to early diagnosis and management. Postgrad Med J 1981; 70: 120-33.

2 Utsinger P D. Zvaifler N J. Weiner S B. Etiology. In: Utsinger P D. Zvaifler N J. Ehrlich G E. eds. Rheumatoid arthritis, etiology. diagnosis, management. Philadelphia: Lippincott. 1985: 21-48.

3 Phillips P E. Infection and the pathogenesis of connective tissue disease. In: Panayi G S. ed. Scientific basis of rheumatology. Edinburgh: Churchill Livingstone. 1982.

4 Steward S M. Alexander W R M. Duthic J J R. Isolation of diphtheroid bacilli from synovial membrane and fluid in rheumatoid arthritis. Ann Rheum Dis 1969: 28: 477-80. 
5 Person R A, Sharp J T, Rawls W E. Attempts to identify viruses and mycoplasmas, connective tissue diseases. Arthritis Rheum 1973; 16: 125.

6 Hodler M M. Pathogenetic model for erosive synovitis; lessons from animal arthritides. Arthritis Rheum 1976; 19: 256-9.

7 Dumonde D C. In: Dumonde D C, ed. Infection and immunology in the rheumatic diseases. Oxford: Blackwell Scientific, 1976.

8 Panush R S. Adenovirus arthritis. Arthritis Rheum 1974; 17: 534-6.

9 Morris E L, Stevens M B. Rheumatoid arthritis-a sequel to HBsAg hepatitis. Am J Med 1978; 64: 859-62.

10 McCormick J N, Duthie J J R, Gerber H, Hart H, Baker S, Marmion B P. Rheumatoid polyarthritis after rubella. Ann Rheum Dis 1978; 37: 266-72.

11 Anonymous. The viral aetiology of rheumatoid arthritis [Editorial]. Lancet 1984; i: 772-4.

12 Simpson R W, McGirty L, Simon L. Association of parvovirus with rheumatoid arthritis in humans. Science 1984; 223: 1425-8.

13 Rahal J J, Milliar J, Nariega E R. Coxsackievirus and adenovirus infection: association with acute febrile and juvenile rheumatoid arthritis. JAMA 1976; 235: 2496-501.
14 Wolf R E. Hyporesponsiveness of lymphocytes to virus antigens in rheumatoid arthritis. Arthritis Rheum 1978; 21: 238-42.

15 Pellegrin M A, Ferrone S, Dietrich M P, Reisfeld R A: Enhancement of SRBC human lymphocyte rosette formation by the sulphydryl compound EAT. Clin Immunol Immuno $\stackrel{\text { ? }}{\rightarrow}$ pathol 1975; 3: 324-8.

16 Treves A J, Yagoda D, Haimovitz A, Ramu N, Rachmilewitz D:D Fuks $\mathrm{Z}$. The isolation and purification of human peripheral blood monocytes in cell suspension. J Immunol Methods 1980; 29: 71-80.

17 Kappler J W, Skidmore B, White J, Marrack P. Antigeno inducible, $\mathrm{H}-2$ restricted, interleukin-2 producing $\mathrm{T}$ celn hybridoma. J Exp Med 1981; 153: 1198-214.

18 Herberman R B. Natural killer cell activity and antibody $\overrightarrow{0}$ dependent cell mediated cytotoxicity. In: Rose N R, Friedman $\mathrm{H} ;-$ Fahey T C, eds. Manual of clinical laboratory immunology. $\vec{\omega}$ Washington DC: American Society of Microbiology, 1986: 310.

19 Lopez C, Kirkpatrick D, Read S E, et al. Correlation between low natural killing of fibroblasts infected with herpes simplexe virus type I and susceptibility to herpes virus infections. $J$ Infect Dis 1983; 147: 1030-5.

20 Quinan G U, Kimoni N, Rook A H, et al. Cytotoxic T cells in cytomegalovirus infection. N Engl J Med 1982; 307: 6-13. 